\title{
OPTIMIZING A LIFE CYCLE ASSESSMENT-BASED DESIGN DECISION SUPPORT SYSTEM TOWARDS ECO-CONSCIOUS ARCHITECTURE
}

\author{
MAHMOUD GOMAA, TAREK FARGHALY \& ZEYAD EL SAYAD \\ Faculty of Engineering, Alexandria University, Egypt
}

\begin{abstract}
Within the rapid growth of the energy demand of buildings, cities start to look at ways to shift towards more sustainable solutions that seek the reduction of energy consumption. In the last few decades, Egypt has witnessed a high rate of residential sector investments to accommodate the population inflation. As a result, such buildings in the residential sector consume the highest rates of energy exhaustion to meet the requirements of heating, cooling, and lighting; with the largest amount of burdens, the environment has to afford. Consequently, it is essential to consider energy control and careful analysis of environmental impacts as an essential part of the design of residential buildings. Life Cycle Assessment has gained significant attention in the study of energy control. It helps to analyze the energy patterns and environmental impacts of every single parameter engaged in the design of buildings. However, its complexity limits its integration into the conventional design process. Which lead to the need of engaging computer-aided design techniques and parametric approaches for the easiness of application. This research aims at developing a framework that achieves a reasonable integration between LCA and the traditional design process focusing on early design stages. It provides architects and designers with a structured methodology that enables them to achieve sustainability goals in their designs. The study follows a framework that firstly examines previous research on LCA. Secondly, it highlights the early design decisions and measures their effect on the final output using parametric tools. Lastly, it examines the validation of the developed framework by the implementation of a selected case study. This helps to carry out design optimization based on LCA in the design process.
\end{abstract}

Keywords: sustainability, LCA, environmental impacts, early design stages, parametric approach.

\section{INTRODUCTION}

In the last few decades, Egypt has witnessed a rapid rate of increase in the investments of residential buildings due to the population growth and the concentration of the majority of inhabitants in the Nile Delta of Egypt. The Egyptian population is now estimated as $102,976,017$ by the Central Agency for Public Mobilization and Statistics (CAPMAS) as of Monday, November 2, 2020 [1].

To face this challenge many expansions have been made in the residential sector to accommodate this inflation, with the focus on building quantities, not the quality of living. Most of these buildings were erected without paying attention to the environmental consideration at the early stages, which led to an excess of energy consumption due to active air-conditioning to afford thermal comfort and well-lit indoor spaces.

As a result, building energy consumption has been increasing to meet the requirements of cooling and electric lighting. Fig. 1 shows that $39.6 \%$ of total electrical energy consumption goes to the residential sector in Egypt. This ratio is relatively high when compared to industry or other purposes due to the continued urban expansion under the current conditions in the country and the ongoing increase in the use of electrical appliances, especially air conditioners due to high temperatures during summer. 


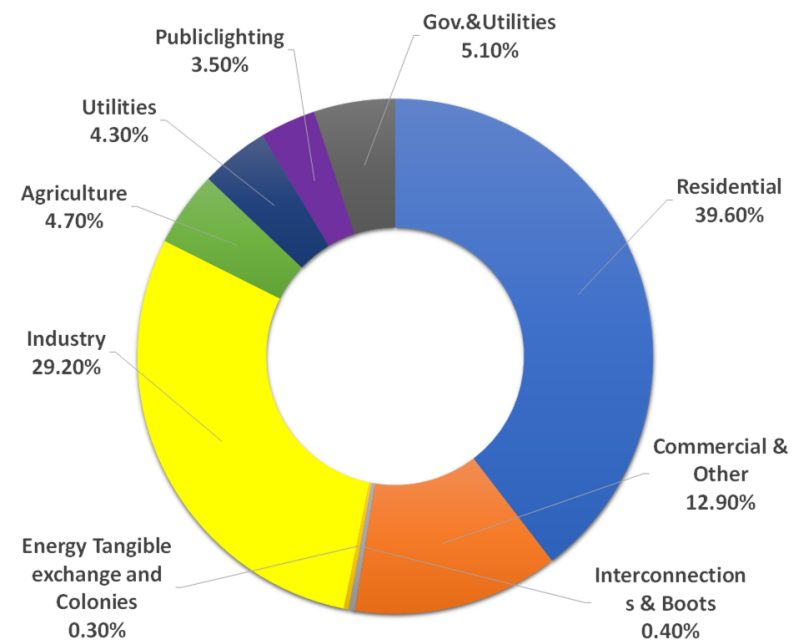

Figure 1: Electricity energy distribution [2].

In addition, the residential buildings in Egypt compromise more than $70 \%$ of the building sector which makes them an essential part of achieving positive outcomes of energy-saving plans. The design and configuration of energy-efficient residential units are likely to solve the energy crisis in Egypt [3]. Such critics require interventions based on the environmental point of view that seeks to improve the quality of life while reducing the negative effects on the environment.

Consequently, more sustainable construction solutions have to be integrated into the industry of residential sector. Agenda 21 on sustainable construction defines it as a complete approach that aims to preserve the relationship between the natural and built environment and build settlements that protect human dignity and motivate equity. It is a practice that aims to raise the quality of life for residents by maintaining a balanced relation between the different demands of people and affordable possibilities [4]. Nevertheless, as for developing countries, the application of sustainability guidelines in the construction sector faces multiple barriers such as poverty, technological inertia, low urban investment, inadequate data, lack of interest in the application of sustainability, and the absence of integrated studies [4].

This paper aims at investigating the importance of applying LCA as a tool to assist architects and designers in the evaluation of environmental impacts starting from the early design stages. It offers a methodology of the integration between LCA and the conventional design process. To test the hypothesis of the developed methodology, the research provides an analysis of a case study in Alexandria, Egypt. It provides simulations and analysis of energy for the selected case study and argues that early design decisions would lead to lower consumption of energy and better environmental performance.

\section{LITERATURE REVIEW}

\subsection{Life cycle assessment}

Since architects have been increasingly interested in integrating environmental aspects and energy control into their designs, many tools, approaches, and methods have been created 
for application in the architectural design process. Energy analysis and modeling tools help to predict environmental impacts and calculate needed energy for buildings as well as reducing operational energy. LCA is one of these tools, it allows architects and designers to examine the environmental behavior of buildings procurement, construction, operation, and decommissioning.

As mentioned by Bayer et al. [5], LCA is believed to aid the architectural design decision-making process. LCA is now being developed as a tool to analyze the environmental impact to control and reduce the negative effects of the process. Besides, it is considered essential for a wide range of professions including ecologists, chemists, and all other fields that seek to understand and reduce the negative impacts of any manufacturing process.

Based on the conceptualization of ISO-14040, LCA consists of four phases as shown in Fig. 2; (1) goal and scope definition: In this phase, some issues should be cleared, such as the reason for applying LCA study, the application areas of the LCA results, the function of the product system, the product system boundaries, and data category [5], (2) Life Cycle Inventory Analysis (LCI): This phase involves data collection and calculation to quantify inputs and outputs of materials and energy associated with a product system under study, (3) Life Cycle Impact Assessment (LCIA): It consists of several elements classification, characterization, normalization, and weighting, and (4) Interpretation: The quantitative results coming from steps 2 and 3 are interpreted qualitatively in order to identify significant issues.

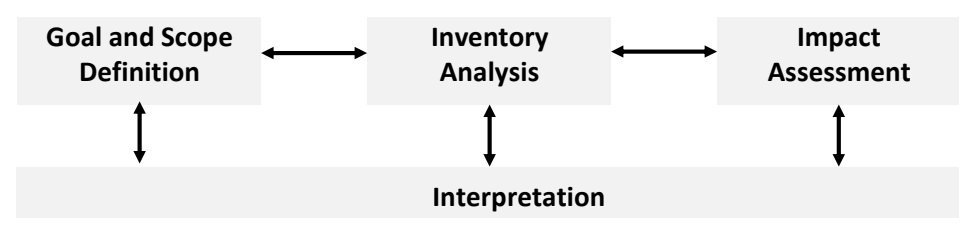

Figure 2: Phases of LCA [6].

Environmental impact categories are measurements of the amount of emissions compared to the environmental impacts that they cause. The impact is always given as a ratio of the quantity of the impact per functional unit of produced product (building or materials). Each category is an indicator of the contribution of a product to a specific environmental problem. These categories are defined by the Life Cycle Impact Assessment (LCIA) methods described below. A set of the environmental impact categories to many LCA methods are provided in Table 1 [5].

LCA can be applied to any product or service, including buildings, to evaluate the environmental impacts of their life cycles [7]. More specifically, the LCA framework has been defined for the building and construction sector as a methodology that provides complete guidelines for applying LCA in that sector [8]. The life cycle of buildings is divided into three main stages with multiple modules as shown in Table 2.

- $\quad$ The first stage includes from module A1 to module A5, this stage is divided into two phases of (1) product phase from module A1 to module A3, it is a cradle to gate stage, meaning all processes until the factory's gate, which contains all the used materials in the building, and (2) construction stage from module A4 and module A5, it considers the transportation of building materials from the factory's gate to the construction site, besides all the construction and installation work in site. 
Table 1: Output-related parameters [5].

\begin{tabular}{|l|l|c|c|}
\hline Impact category & Parameter & Abbreviation & Unit \\
\hline Climate change & Global warming potential & $\mathrm{GWP}$ & $\mathrm{kg} \mathrm{CO}_{2}$-equiv. \\
\hline Ozone depletion & Ozone depletion potential & $\mathrm{ODP}$ & $\mathrm{kg} \mathrm{R11-equiv.}$ \\
\hline $\begin{array}{l}\text { Acidification of soil and } \\
\text { water }\end{array}$ & Acidification potential & $\mathrm{AP}$ & $\mathrm{kg} \mathrm{SO}_{2}$-equiv. \\
\hline Eutrophication & Eutrophication potential & $\mathrm{EP}$ & $\mathrm{kg} \mathrm{PO}^{3}$-equiv. \\
\hline $\begin{array}{l}\text { Formation of photo } \\
\text { oxidants }\end{array}$ & $\begin{array}{l}\text { Photochemical ozone creation } \\
\text { potential }\end{array}$ & $\mathrm{POCP}$ & $\mathrm{kg} \mathrm{CH}_{4}$-equiv. \\
\hline Abiotic resource depletion & $\begin{array}{l}\text { Abiotic resource depletion } \\
\text { potential element }\end{array}$ & $\mathrm{ADPe}$ & $\mathrm{kg} \mathrm{Sb}$-equiv. \\
\hline Abiotic resource depletion & $\begin{array}{l}\text { Abiotic resource depletion } \\
\text { potential fossil }\end{array}$ & $\mathrm{ADPf}$ & $\mathrm{Mj}$ \\
\hline
\end{tabular}

Table 2: Stages of LCA [9].

\begin{tabular}{|c|c|c|c|c|c|c|c|c|c|c|c|c|c|c|c|}
\hline \multicolumn{3}{|c|}{ Product stage } & \multicolumn{2}{|c|}{$\begin{array}{c}\text { Process } \\
\text { stage }\end{array}$} & \multicolumn{7}{|c|}{ Use stage } & \multicolumn{4}{|c|}{ End of life stage } \\
\hline A1 & A2 & $\mathrm{A} 3$ & A4 & A5 & B1 & B2 & B3 & B4 & B5 & B6 & B7 & $\mathrm{C} 1$ & $\mathrm{C} 2$ & $\mathrm{C} 3$ & $\mathrm{C} 4$ \\
\hline 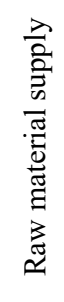 & 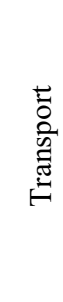 & 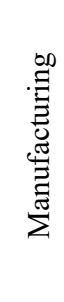 & 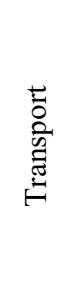 & 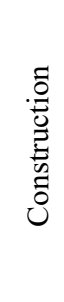 & $\stackrel{0}{\infty}$ & 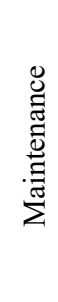 & $\begin{array}{l}\stackrel{\vec{\pi}}{0} \\
\stackrel{2}{2}\end{array}$ & 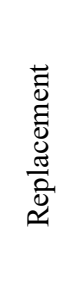 & 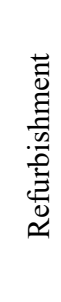 & 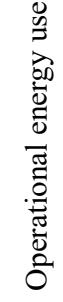 & 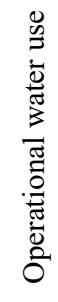 & 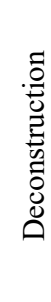 & 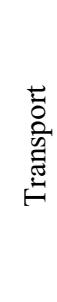 & 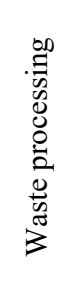 & $\begin{array}{l}\overline{0} \\
0 \\
0 \\
.02 \\
\overline{0}\end{array}$ \\
\hline
\end{tabular}

- $\quad$ The second stage is called the use phase, it includes modules from B1 to module B7. It covers all the operations linked with the building throughout its lifespan. The modules are named use, maintenance, repair, replacement, refurbishment, operational energy use, and operational water use.

- $\quad$ The third stage is called the end-of-life stage, it includes modules from module $\mathrm{C} 1$ to module $\mathrm{C} 4$. This stage is associated with the building deconstruction, the demolishing, transportation, sorting, and treating wastes, and the final disposal [9].

Although LCA is a holistic approach, it has some limitations that should be clear during its application. The main challenges are (1) potentials instead of absolute values: LCA results are not able to predict precise or absolute environmental impacts, practitioners have to rely on models that are only valid within a certain context [10], (2) place independence: LCA is not able to quantify impacts and risks on the environment at a specific location [11], (3) time independence: The models lack temporal dimensions, making it impossible to specify the point in time that emission occurs [12], (4) limitations of impact categories: the impact categories cover a wide range of environmental aspects, but do not cover all relevant environmental aspects [13], (5) assumptions: although LCA aims to be science-based, it involves many technical assumptions and value choices. These assumptions can have a great influence on the results [14], and (6) uncertainties: LCA involves numerous uncertainties such as parameter uncertainties, model uncertainties, and normative uncertainties [10]. 
LCA studies cannot be completed with the same level of detail, especially in the construction sector. Users like architects or building designs would like to include environmental aspects in an early stage of a building design but without that amount of required details. Simplified approaches are very essential especially in buildings because they consist of many different products and materials, meaning a full detailed LCA is very difficult [15]. To distinguish between different simplification approaches for the LCA of buildings, the EebGuide introduces three categories with increasing levels of detail: screening LCA, simplified LCA, and complete LCA as shown in Table 3 [16].

Table 3: Types of LCA [16].

\begin{tabular}{|l|l|l|l|}
\hline & Screening LCA & Simplified LCA & Complete LCA \\
\hline $\begin{array}{l}\text { Number of } \\
\text { indicators } \\
\text { employed }\end{array}$ & $\begin{array}{l}\text { At least 1 or two } \\
\text { indicators }\end{array}$ & Reduced indicator set & $\begin{array}{l}\text { A comprehensive set } \\
\text { listed in ILC Handbook }\end{array}$ \\
\hline Type of data & Generic LCA data & $\begin{array}{l}\text { Generic or average } \\
\text { LCA data }\end{array}$ & Specific LCA (EPDs) \\
\hline $\begin{array}{l}\text { Mandatory } \\
\text { life cycle } \\
\text { modules }\end{array}$ & A1-A3, B6, B7 & $\begin{array}{l}\text { A1-A3, B4, B6, B7, } \\
\text { C3, C4, D }\end{array}$ & $\begin{array}{l}\text { A1-A5, B1-B7, C1-C4, } \\
\text { D }\end{array}$ \\
\hline $\begin{array}{l}\text { Mandatory } \\
\text { building parts } \\
\text { to be included }\end{array}$ & $\begin{array}{l}\text { Roof, exterior } \\
\text { walls, load- } \\
\text { flooring structure, } \\
\text { windows, }\end{array}$ & $\begin{array}{l}\text { Roof, exterior walls, } \\
\text { floor slabs, windows, } \\
\text { floor finish, foundation }\end{array}$ & $\begin{array}{l}\text { Roof, exterior walls, } \\
\text { load-bearing structure, } \\
\text { floor slabs, windows, } \\
\text { floor finish, foundation, } \\
\text { wall finishes, doors, } \\
\text { building services } \\
\text { including heating or } \\
\text { cooling, lighting, lifts, } \\
\text { water system }\end{array}$ \\
\hline
\end{tabular}

\subsection{Energy calculations}

Many different types of data are needed for calculating the LCA of a building. This data can be broadly classified as being required either for the embodied or the operational impact calculation. This classification is clarified in Table 4.

Table 4: Categories of needed data for energy calculations (researcher).

\begin{tabular}{|l|l|}
\hline Embodied impact & \multicolumn{1}{c|}{ Operational impact } \\
\hline $\begin{array}{l}\text { Environmental data for building materials and } \\
\text { services }\end{array}$ & Energy data for energy carriers \\
\hline $\begin{array}{l}\text { Data on the reference service lives (RSL) of } \\
\text { building materials }\end{array}$ & $\begin{array}{l}\text { Data for energy demand calculation } \\
\text { Physical properties, climate data, } \\
\text { and user data }\end{array}$ \\
\hline
\end{tabular}

2.3 Integration between the architectural design process and LCA

According to the Royal Institute of British Architects (RIBA), the major planning process is divided into three stages, namely, pre-design stage, design stage, execution stage. Each 
stage is divided into substages. The focus of this paper is on the design process which is divided into three main steps. These steps are concept design, developed design, and technical design [17] as illustrated in Table 5, the sub-stages are provided in detail in the following section.

Table 5: Phases of the design process [17].

\begin{tabular}{|c|c|c|c|c|c|c|c|}
\hline \multicolumn{2}{|c|}{ Pre-design } & \multicolumn{3}{c|}{ Design stage } & \multicolumn{3}{c|}{ Execution stage } \\
\hline $\begin{array}{c}\text { Strategic } \\
\text { definition }\end{array}$ & $\begin{array}{c}\text { Preparation } \\
\text { and brief }\end{array}$ & $\begin{array}{c}\text { Concept } \\
\text { design }\end{array}$ & $\begin{array}{c}\text { Developed } \\
\text { design }\end{array}$ & $\begin{array}{c}\text { Technical } \\
\text { design }\end{array}$ & Construction & $\begin{array}{c}\text { Handover } \\
\text { and closeout }\end{array}$ & In use \\
\hline
\end{tabular}

- The concept design stage: it is a stage where the initial design idea is created, the function's requirements for each zone are organized, and the design tasks are specified by geometric parameters including volume, orientation, etc.

- The developed design stage: it is the stage that includes decisions on the typology of construction - whether a skeleton structure or bearing walls will be used.

- The technical design stage: it is the stage that studies building materials, the specific connections between different materials, and the HVAC systems in addition to the increasing level of details in the building model.

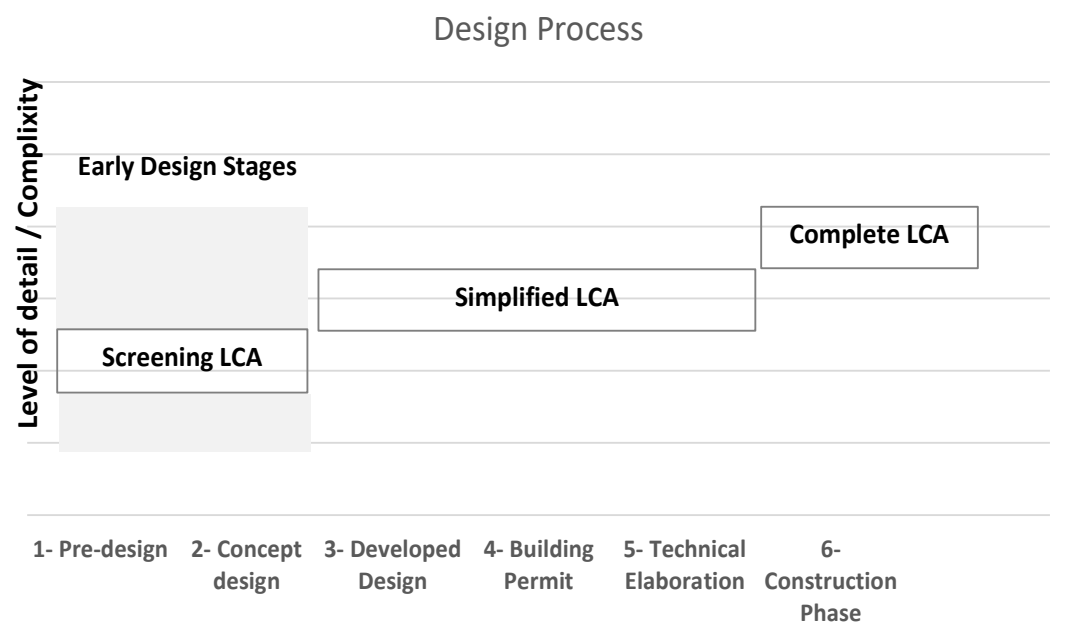

Figure 3: Types of LCA and integration of early design stage [18].

\subsection{Methodology}

The proposed methodology is created to prove that integrating LCA into the design process is essential to achieve lower environmental impacts. It is divided into five major steps. These steps compromise a workflow that represents an interconnected closed loop as shown in Fig. 4. An explanation of each of these steps is offered as follows:

Step one represents the data input phase which includes all needed parameters to be provided in the early design stage. One of the essential parameters is building geometry. In such a phase of design, it is needed to provide a low detailed geometry model which consists of exterior walls, interior walls, roofs, and slabs. This geometry is presented 


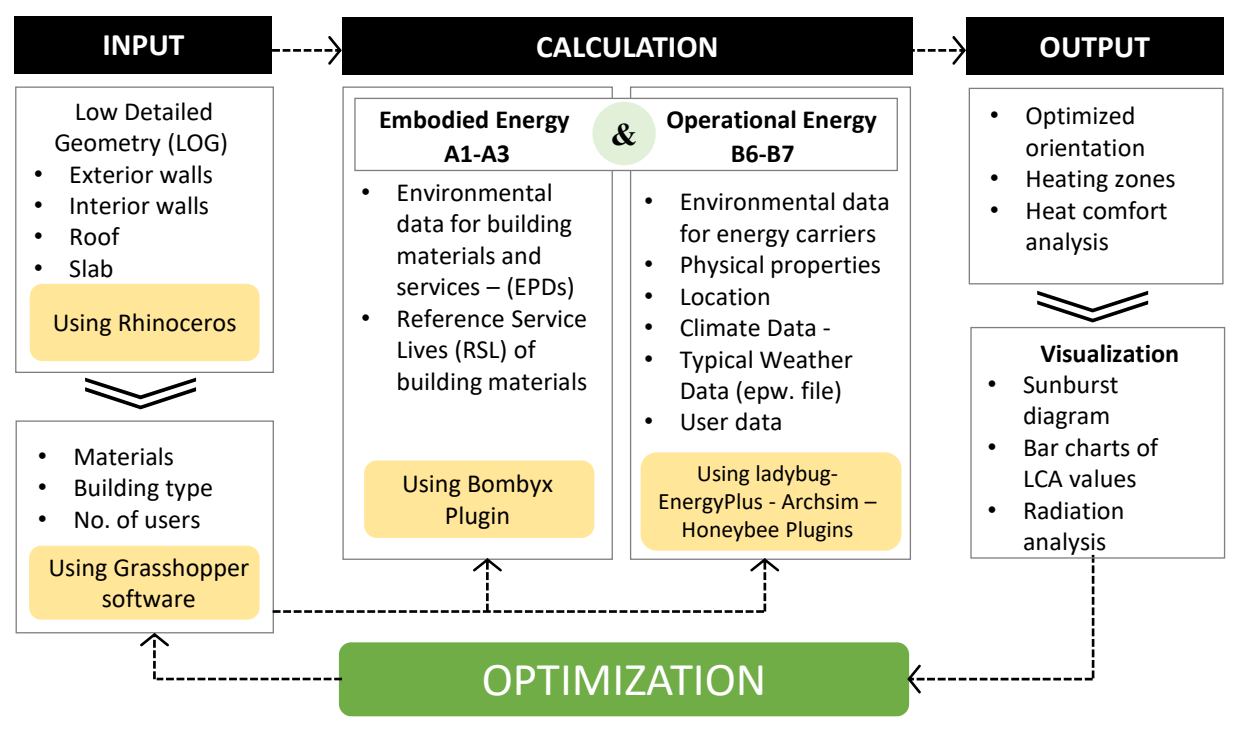

Figure 4: A research framework (researcher).

through a 3D CAD model using a parametric tool such as Rhinoceros 3D. This tool enables designers to alternate and change parameters easily and generate multiple solutions. Other important inputs include assigning materials, building type, and the number of users. Together these inputs provide basic orientation towards the optimization process.

Step two represents the calculation phase. It is divided into two sub-phases of embodied energy calculation and operational energy calculation. On the one hand, embodied energy calculation depends on the environmental data for each material used in the building as the firm which produces this material spreads environmental product declarations (EPDs) files containing this environmental data. It also depends on the reference service life, meaning the lifetime for each material. This data is a part of the database of a Bombyx plugin used to calculate LCA through Grasshopper.

On the other hand, operational energy calculation depends on the environmental data for energy carriers, physical properties of building materials such as density, thermal conductivity, and heat capacity. Besides, it considers building location in order to go with the proper climate data for various building zones. In addition to the user data which represents the need for cooling or drying the indoor comfortability for users. To calculate the operational energy demand, some plugins for Grasshopper are used such as EnergyPlus, Honeybee, Archsim, and ladybug. They are all connected together in order to get results depending on the same database.

Step three represents the outputs, all possible results after the step of energy calculation. These results indicate the energy demand for the building due to the used material, the arrange of comfortability in each zone in the building and the amount of lighting which enters the building, and the amount of heat that faces the building.

Step four represents the visualization phase. This phase is associated with converting all these results into graphs in order to be easy for architects to assess these results. This phase proves easiness in the comparison and optimization process. Most commonly used presentations include bar charts, color-scaled heat zoning charts, or sunburst diagrams. 
Step five represents the optimization phase. It is the final stage that compares all the data integrated into the process starting from the input phase. This comparison tends to examine which of the developed scenarios are best in terms of environmental impact. This step serves as an essential part of the systematic design process as it leads to a better understanding of building behavior before conducting detailed design projects.

\subsection{Results and discussion}

The developed methodology is implemented in a residential area located in Alexandria city, Egypt. The selected project is one of the recent residential expansions that are built to accommodate the population inflation of Alexandria city. It is located on the western edge of the city. The results reflect the steps of the developed methodology. Firstly, the examination of initial geometries using Rhino reveals that the existing orientation of building geometry leads to an inflation of energy consumption due to high amounts of radiation as shown in Table 6 . An optimized solution for orientation is to rotate the building by $90^{\circ}$ to reduce the amount of radiation and energy consumption accordingly.

Table 6: Optimization of building orientation using a low detailed geometry model.

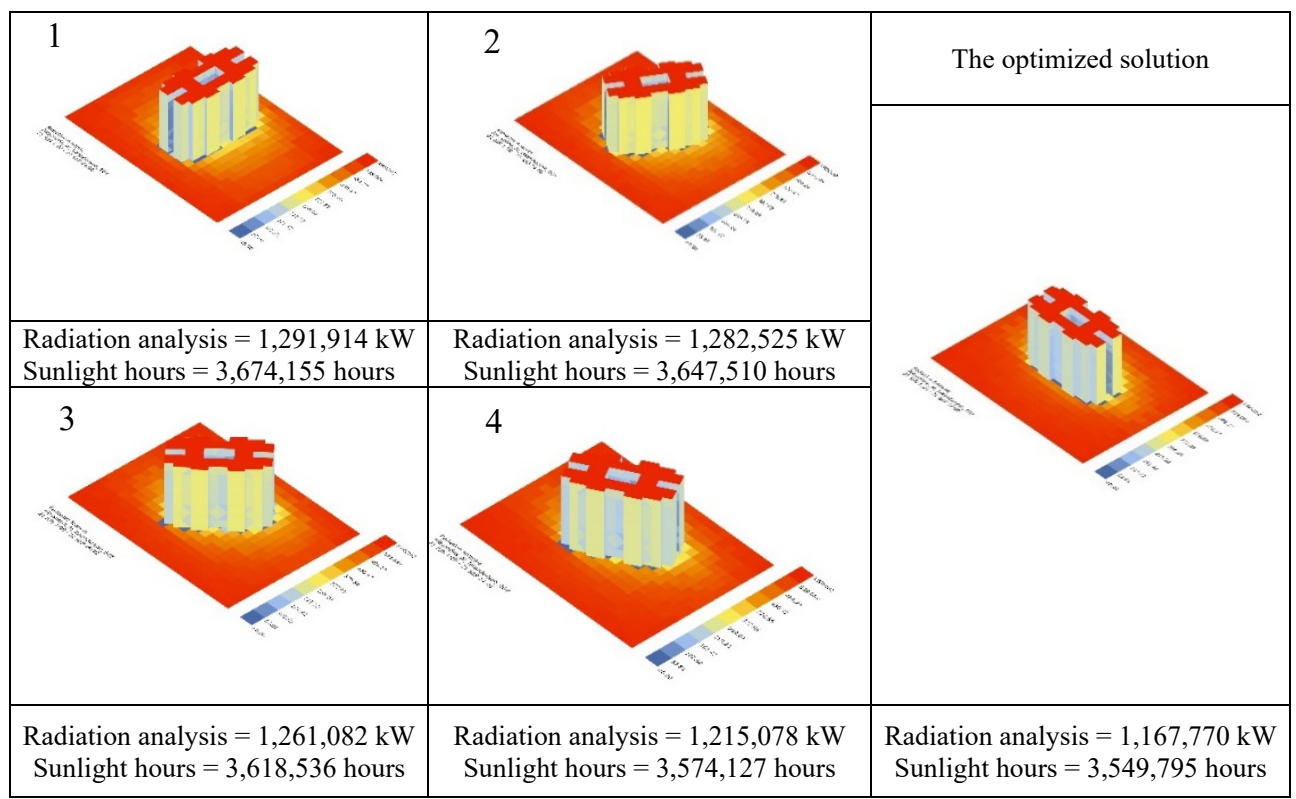

The existing orientation is directed as trail no 1 , in this case, the total amount of solar radiation on the outer surface of the building during the summer zone is 1,291,914 kW. Where the number of hours of direct sunlight received by the building is $3,674,155$ hours. These values are decreasing when rotating the building (refer to Table 6). A clear reduction is clear starting from trail no 2 after rotating the building by $30^{\circ}$, then trail no 3 after rotating the building $45^{\circ}$, and reaching a rotation by $60^{\circ}$ in trial no 4 . The least amount of radiation analysis and in sunlight hours is reached when the building is rotated to be $90^{\circ}$. From these results, building orientation is one of the most important factors which has a significant effect on designing a building and has a noticeable impact on the energy demand of the building to realize the comfortability for building users. 
After getting the optimized solution in terms of orientation, it is time to compare between the best solution and the existing one in order to know how important the direction parameter affects the quality of the design and the effectiveness of the outer surroundings. A new simulation is applied to two cases of different orientations. This simulation is called radiation analysis as it allows to calculate the radiation falling on the input geometry using a sky matrix from the select sky mxt component. This type of radiation study is useful for building surfaces, such as windows, where it might be interesting in the energy that can be collected.

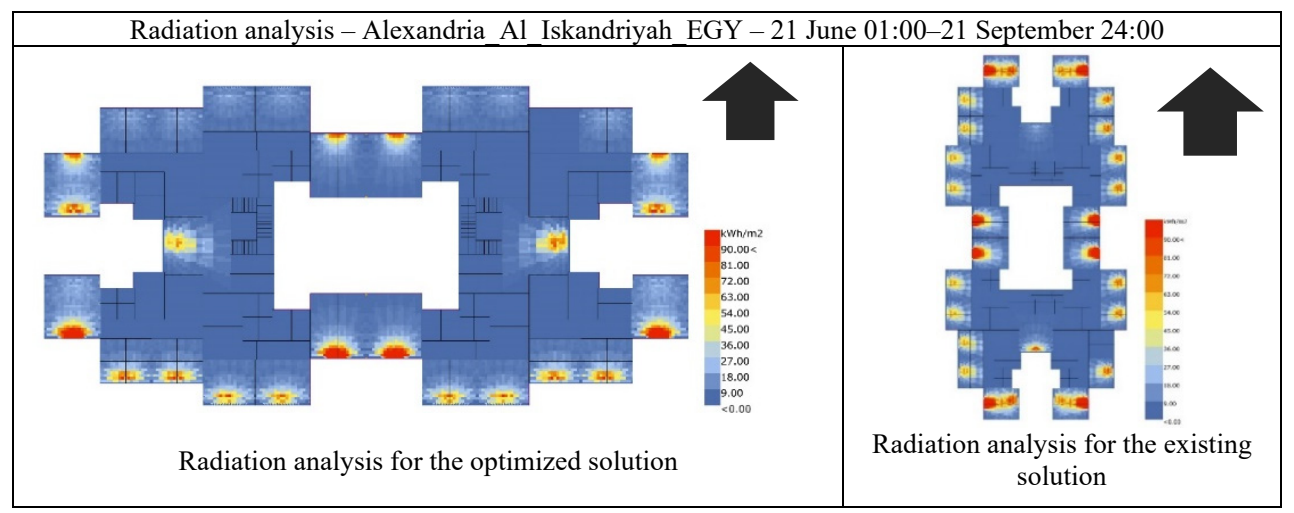

Figure 5: Radiation analysis of two distinct solutions that vary in terms of orientation (researcher).

It is clear from the above simulation that heat gain in the exciting orientation of the building is higher than the optimized solution. This means that there would be higher energy consumption in the exciting case to exchange this amount of heat with cooling to achieve thermal comfort in indoor spaces. On the other hand, the optimized solution would require a lower energy amount due to lower amounts of solar radiation.

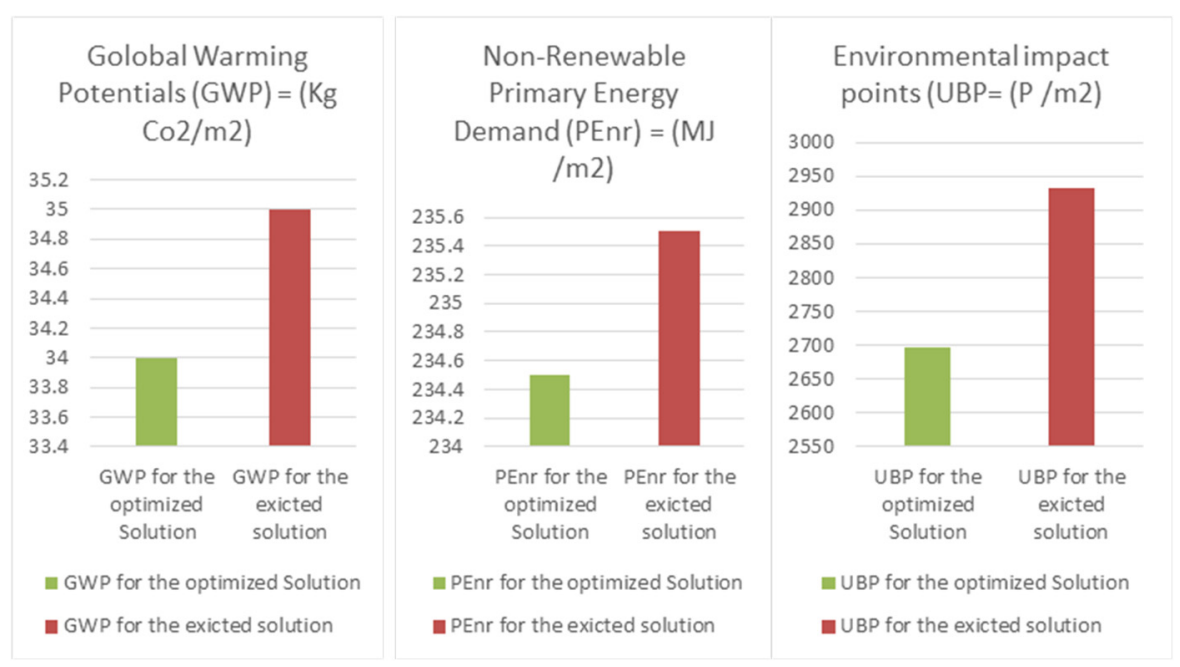

Figure 6: A comparative analysis of LCA values two scenarios (researcher). 
In order to adapt the exciting solution, a set of modifications are offered to minimize the heat gain of the building to reduce the consumed energy for cooling. These modifications include adding a double wall thickness in the east and west facades. In addition to a thermal insulation material to stop gaining heat inside spaces. After applying these modifications and getting a satisfying result of energy an LCA calculation has been made to compare between the two cases and to measure the impact of the used materials on the outer surroundings. This reveals that even an adapted solution would lead to higher impacts on the environment. Hence, applying LCA at the early stages of design is essential to reduce environmental impacts.

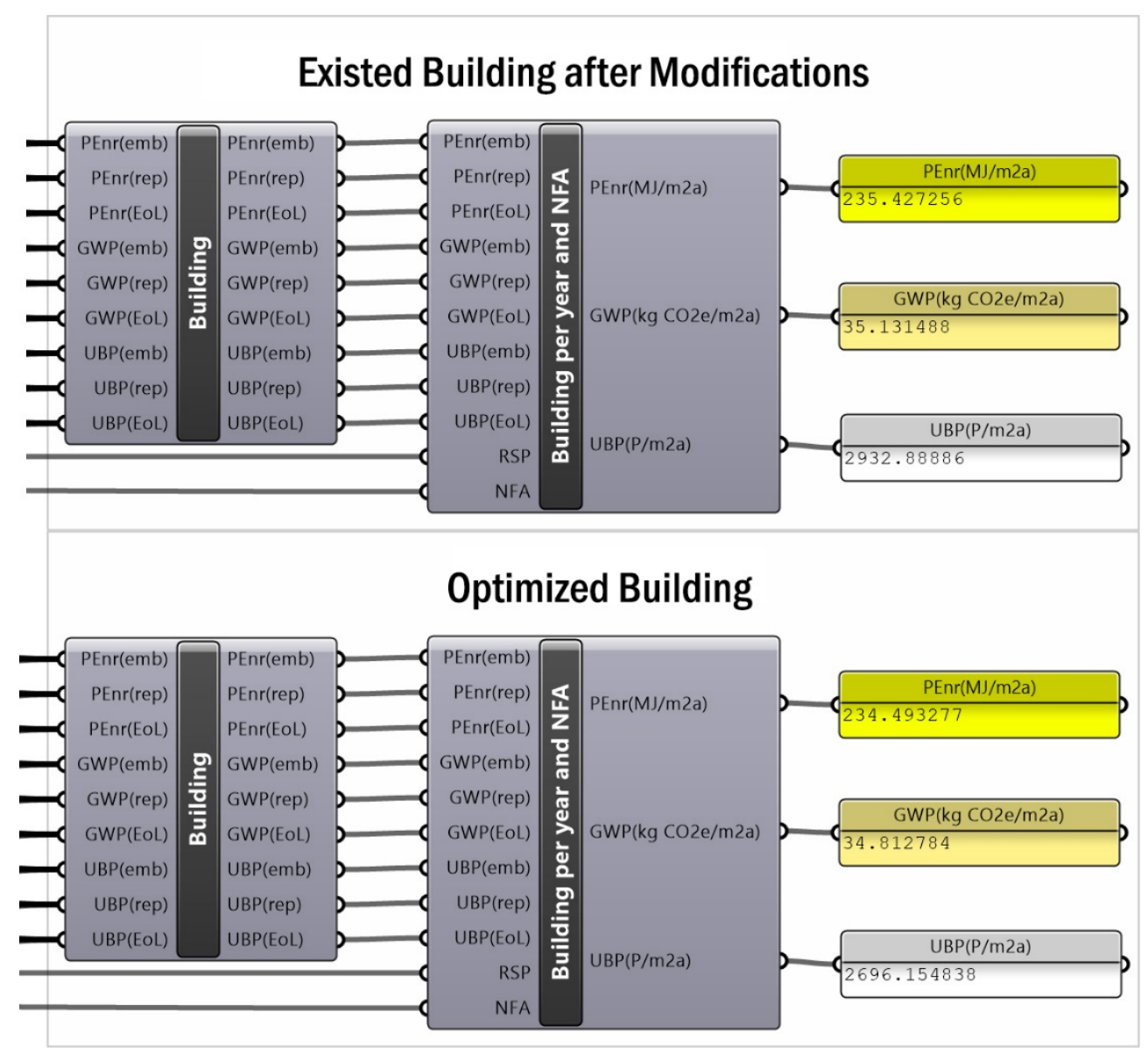

Figure 7: Comparison between the existing building (with proposed modifications) and the optimized solution (researcher).

\section{CONCLUSION}

LCA has become an increasingly important topic in the design and construction of buildings. It is agreed that LCA is essential to be integrated into the design process. However, its application by designers and architects is not yet widely employed due to complexity and time consumption. This research provided a methodology that aims at 
integrating LCA in the early stages of the architectural design process. It seeks to achieve a simple framework that architects can easily follow when conducting new designs in order to reduce energy demand and environmental impacts accordingly. This methodology tends to minimize the effort of performing LCA for buildings after finishing it by introducing the interconnection between a screening LCA into the design process in the early design stage. Since design decisions are very important in the early design stages, reducing the environmental impacts became an essential matter to be considered throughout designing a building especially the residential buildings.

\section{REFERENCES}

[1] CAPMAS, Population estimation by the Central Agency for Public Mobilization and Statistics. 2020. https://www.capmas.gov.eg/.

[2] MERE, The Ministry of Electricity and Renewable Energy of Egypt annual energy report. 2019.

[3] Aldali, K.M. \& Moustafa, W.S., An attempt to achieve efficient energy design for high-income houses in Egypt: Case study: Madenaty city. International Journal of Sustainable Built Environment, 5(2), pp. 334-344, 2016.

[4] CIB U-I, Agenda 21 for Sustainable Construction in Developing Countries, Conseil International du Batiment: Rotterdam, 2002.

[5] Bayer, C., Gamble, M., Gentry, R. \& Joshi, S., AIA Guide to Building Life Cycle Assessment in Practice, The American Institute of Architects: Washington, DC, 2010.

[6] ISO14040. Environmental management - Life cycle assessment - Principles and framework (ISO 14040:2009), 2009.

[7] Frostell, B., Life cycle thinking for improved resource management: LCA or? 2013.

[8] Kotaji, S., Schuurmans, A. \& Edwards, S., Life-Cycle Assessment in Building and Construction: A State-of-the-Art Report, 2003, Setac, 2003.

[9] Lasvaux, S. et al., Achieving consistency in life cycle assessment practice within the European construction sector: The role of the EeBGuide InfoHub. The International Journal of Life Cycle Assessment, 19(11), pp. 1783-1793, 2014.

[10] Klöpffer, W. \& Grahl, B., Life Cycle Assessment (LCA): A Guide to Best Practice, John Wiley \& Sons, 2014.

[11] König, H. \& De Cristofaro, M.L., Benchmarks for life cycle costs and life cycle assessment of residential buildings. Building Research and Information, 40(5), pp. 558-580, 2012.

[12] Collinge, W.O., Landis, A.E., Jones, A.K., Schaefer, L.A. \& Bilec, M.M., Dynamic life cycle assessment: Framework and application to an institutional building. The International Journal of Life Cycle Assessment, 18(3), pp. 538-552, 2013.

[13] Finnveden, G., On the limitations of life cycle assessment and environmental systems analysis tools in general. The International Journal of Life Cycle Assessment, 5(4), p. 229, 2000.

[14] Guinée, J.B., Huppes, G. \& Heijungs, R., Developing an LCA guide for decision support. Environmental Management and Health, 2001.

[15] Wittstock, B. et al., EeBGuide guidance document part B: Buildings. Operational guidance for life cycle assessment studies of the energy-efficient buildings initiative. pp. 1-360, 2012.

[16] Gantner, J. et al., EeBGuide Guidance Document Part B: Buildings. Operational Guidance for Life Cycle Assessment Studies of the Energy Efficient Building Initiative, Fraunhofer Verlag, 2015. 
50 Computational Methods and Experimental Measurements XX

[17] Sinclair, D., Design Management: RIBA Plan of Work 2013 Guide, Routledge, 2019.

[18] Kiss, B. \& Szalay, Z. (eds), The impact of decisions made in various architectural design stages on life cycle assessment results. Applied Mechanics and Materials, 2017. 